\title{
Application of irradiation-then-nitridation to improve the radiation hardness in MOS gate dielectrics
}

\author{
Kuo-Chung Lee * , Jenn-Gwo Hwu \\ Department of Electrical Engineering, Room 446, National Taiwan University, Taipei, Taiwan, ROC
}

Received 12 December 1994; accepted for publication 30 June 1995

\begin{abstract}
In this paper, the irradiation-then-nitridation (ITN) method was suggested to prepare oxynitrides. After ${ }^{60} \mathrm{Co} 1 \mathrm{Mrad}$ irradiation, oxides were nitrided in $\mathrm{N}_{2} \mathrm{O}$ to become oxynitrides. They are more radiation hard than those nitrided in $\mathrm{N}_{2} \mathrm{O}$ directly. The difference can be explained by assuming that ITN process introduces more nitrogen $\mathrm{SiO}_{2} / \mathrm{Si}$ interfaces and hence improves radiation hardness.
\end{abstract}

\section{Introduction}

Recently, it has been suggested that oxynitrides are candidates in the next generation IC process used as the dielectric material. Because of the formation of strong $\mathrm{Si}-\mathrm{N}$ bonds and stress compensation of better $\mathrm{Si}-\mathrm{N}$ bonds at the $\mathrm{SiO}_{2} / \mathrm{Si}$ interface, oxynitrides exhibit better performance and are more realiable than conventional oxides [1-5]. $\mathrm{N}_{2} \mathrm{O}$ nitridation of thermal oxides is one of the methods used to incorporate nitrogen into the gate oxides. It is superior to RNO (nitridation of thermal oxide in pure $\mathrm{NH}_{3}$ followed by pure $\mathrm{O}_{2}$ reoxidation) since no hydrogen induced electron trapping problem occurs $[1,6,7]$. However, only a small amount of nitrogen atoms are incorporated into $\mathrm{SiO}_{2}$ very slowly when the conventional $\mathrm{N}_{2} \mathrm{O}$ nitridation method [8] is used. Therefore, long nitridation time is needed in the conventional $\mathrm{N}_{2} \mathrm{O}$ nitridation process. In this work,

\footnotetext{
" Corresponding author. Tel.: + 886 2363-5251-446.
}

we report on the results of using an irradiation then $\mathrm{N}_{2} \mathrm{O}$ nitration (ITN) method to prepare the $\mathrm{N}_{2} \mathrm{O}$ nitrided oxides. It appears that more nitrogen atoms can be incorporated into oxides by ITN. We found that the ITN-treated oxides are more radiation hard than conventional $\mathrm{N}_{2} \mathrm{O}$ nitrided oxides.

\section{Experimental}

MOS capacitors were fabricated on $8-12 \Omega \cdot \mathrm{cm}$ p-type $\mathrm{Si}(100)$ substrates. Control oxides (about 12 $\mathrm{nm}$ ) were grown in a furnace at $980^{\circ} \mathrm{C}$ in dry $\mathrm{O}_{2}$ for $18 \mathrm{~min}$ and then post oxidation annealed in $\mathrm{N}_{2}$ at the same temperature for $10 \mathrm{~min}$. Some of the samples were irradiated by ${ }^{60} \mathrm{Co}$ with a total dose of $1 \mathrm{Mrad}$. After this, $\mathrm{N}_{2} \mathrm{O}$ nitridations were carried out for non-irradiated and irradiated samples in a rapid thermal annealing system at a pressure of about $0.5 \mathrm{~atm}$. After nitridations, aluminum films were evaporated to form metal-oxide-semiconductor MOS structures. Finally, MOS capacitors were post metallization an- 


\section{Irradiation-Then-Nitridation}

(ITN) Process

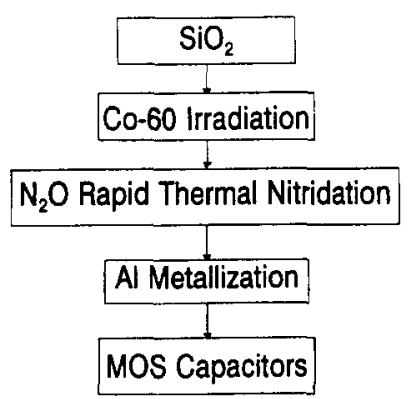

Fig. 1. Flow chart of irradiation-then- $\mathrm{N}_{2} \mathrm{O}$ nitridation (ITN) process.

nealed (PMA) in $\mathrm{N}_{2}$ at $400^{\circ} \mathrm{C}$ for $25 \mathrm{~min}$. Fig. 1 shows the flow chart of the ITN process. The flatband voltage $V_{\mathrm{FB}}$ and the interface trap density $D_{\mathrm{itm}}$ were calculated from the high-low frequency $C-V$ curves. The radiation hardnesses of the conventional and ITN treated $\mathrm{N}_{2} \mathrm{O}$ nitridation samples were determined by measurements performed after ${ }^{60} \mathrm{Co}$ irradiation with a total dose of $1 \mathrm{Mrad}$.

\section{Results and discussion}

Figs. 2 and 3 show the temperature dependences of the flat-band voltage $V_{\mathrm{FB}}$ and midgap interface trap density $D_{\mathrm{itm}}$, respectively, of the conventional and the ITN $\mathrm{N}_{2} \mathrm{O}$ nitrided oxides. It is known that

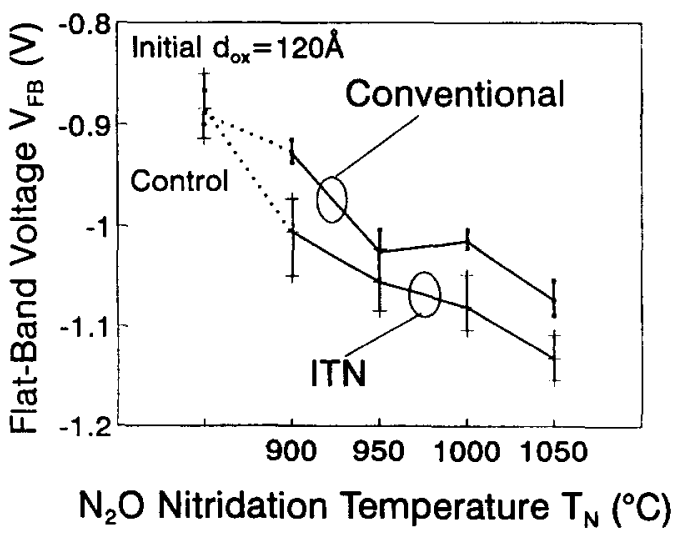

Fig. 2. Flat-band voltage $V_{\mathrm{FB}}$ versus nitridation temperature $T_{\mathrm{N}}$ curves for the ITN and the conventional $\mathrm{N}_{2} \mathrm{O}$-nitrided samples.

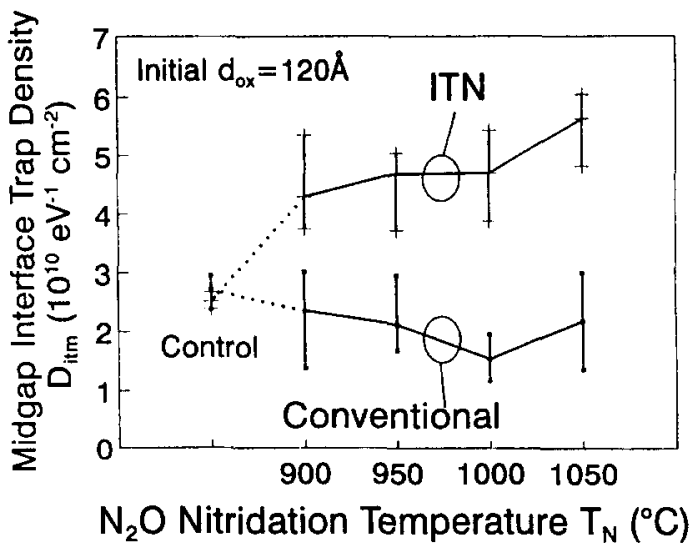

Fig. 3. Midgap interface trap density $D_{\mathrm{itm}}$ versus nitridation temperature $T_{\mathrm{N}}$ curves for the ITN and the conventional $\mathrm{N}_{2} \mathrm{O}$ nitrided samples.

the interface trap density and oxide fixed charges are dependent on the amount of nitrogens incorporated into the oxide. From Figs. 2 and 3, it was found that the two control samples, i.e. samples without nitridations, have almost the same $D_{\text {itm }}$ and $V_{\mathrm{FB}}$. This means that after PMA, the irradiation induced $\Delta D_{\mathrm{itm}}$ and $\Delta V_{\mathrm{FB}}$ was recovered. However, after $\mathrm{N}_{2} \mathrm{O}$ nitridations at various temperatures, the ITN $\mathrm{N}_{2} \mathrm{O}$ nitrided oxides exhibit a large initial $D_{\mathrm{itm}}$ and more negative $V_{\mathrm{FB}}$ than the conventional $\mathrm{N}_{2} \mathrm{O}$ nitrided oxides. This phenomenon may be due to the larger number of nitrogen atoms induced into the ITN oxides. Note that when radiation hardness is the goal there is a trade-off between good initial properties and high radiation resistance $[9,10]$. No one has as yet obtained a radiation hard sample with initial properties superior to those of a conventional sample. Noted also that the nitrogen incorporated into the gate oxide will introduce oxide traps into the bulk oxide and interface traps at the $\mathrm{SiO}_{2} / \mathrm{Si}$ interface. This may explain why the initial conditions of the oxynitride are inferior to those of conventional thermal oxides. Since the $\mathrm{Si}-\mathrm{N}$ bonds are stronger than $\mathrm{Si}-\mathrm{O}$ bonds (the bond energy for $\mathrm{Si}-\mathrm{N}$ and $\mathrm{Si}-\mathrm{O}$ bonds are 4.6 and $4.5 \mathrm{eV}$ respectively), the more nitrogen atoms incorporated into the gate oxide, the higher the radiation hardness of the device. From Figs. 2 and 3, it can be seen that the ITN process introduces more nitrogen atoms into the oxides than the pure $\mathrm{N}_{2} \mathrm{O}$ process does. In addition, it was found that the higher the nitridation tempera- 


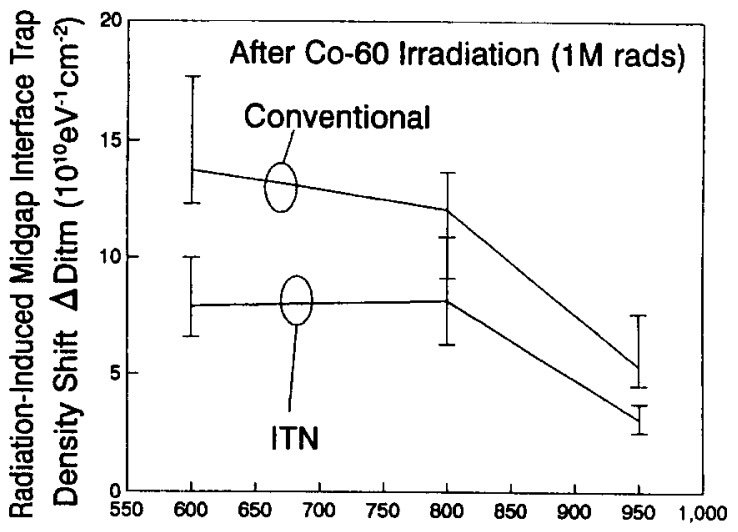

$\mathrm{N}_{2} \mathrm{O}$ Nitridation Temperature $\mathrm{T}_{\mathrm{N}}\left({ }^{\circ} \mathrm{C}\right)$

Fig. 4. Radiation-induced midgap interface trap density shift $\Delta D_{\text {itm }}$ versus nitridation temperature $T_{\mathrm{N}}$ curves for the ITN and the conventional $\mathrm{N}_{2} \mathrm{O}$-nitrided samples after ${ }^{60} \mathrm{Co} 1 \mathrm{Mrad}$ irradiation.

ture $T_{\mathrm{N}}$, the larger the $D_{\mathrm{itm}}$ and the more negative the $V_{\mathrm{FB}}$ for the ITN samples. Higher temperature may introduce more nitrogen atoms into the oxide. However, for the conventional $\mathrm{N}_{2} \mathrm{O}$-nitrided samples, the $D_{\mathrm{irm}}$ decreases gradually with $T_{\mathrm{N}}$. Probably because the more significant annealing effect occurs at higher $T_{\mathrm{N}}$ when the amount of nitrogen atoms is not high enough.

After ${ }^{60} \mathrm{Co}$ irradiation, all samples will be damaged and there will be an interface trap density shift $\Delta D_{\text {itm }}$ and flat-band voltage shift $\Delta V_{\mathrm{FB}}$. Fig. 4 shows

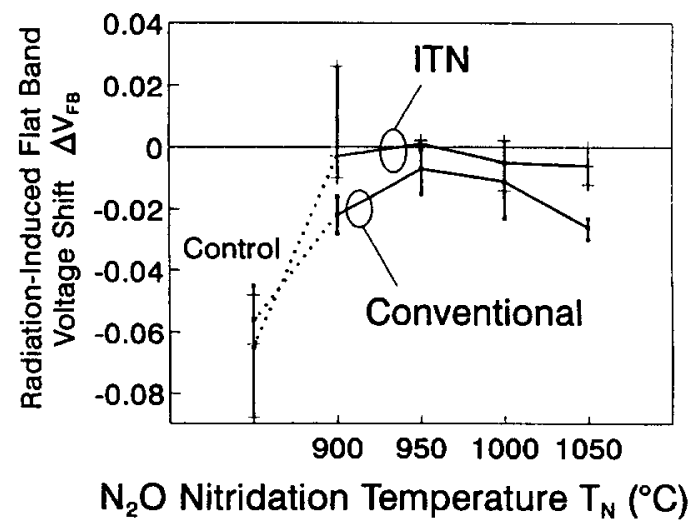

Fig. 5. Radiation-induced flat-band voltage shift $\Delta V_{\mathrm{FB}}$ versus nitridation temperature $T_{\mathrm{N}}$ curves for the ITN and the conventional $\mathrm{N}_{2} \mathrm{O}$-nitrided samples after ${ }^{60} \mathrm{Co} 1 \mathrm{Mrad}$ irradiation.

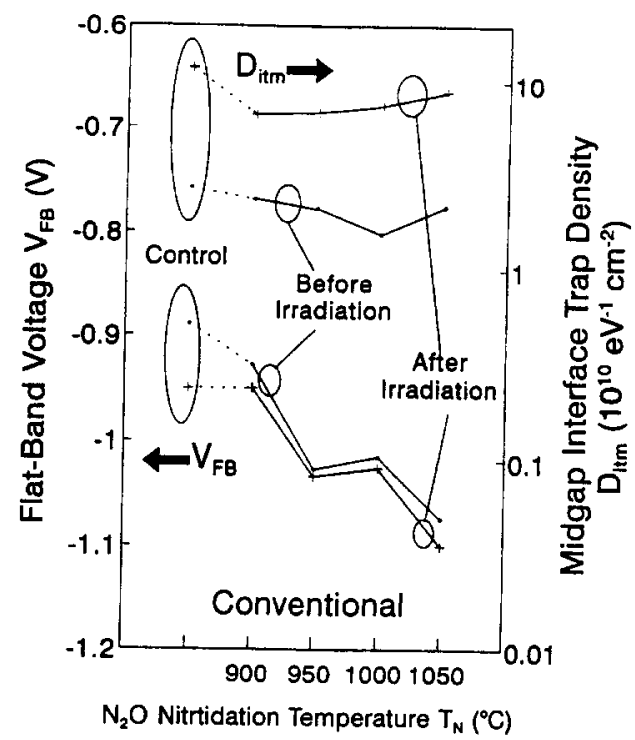

Fig. 6. The flat-band voltage $V_{\mathrm{FB}}$ and midgap interface trap density $D_{\text {itm }}$ versus nitridation temperature $T_{\mathrm{N}}$ curves for the conventional $\mathrm{N}_{2} \mathrm{O}$-nitrided samples before and after ${ }^{60} \mathrm{Co} 1 \mathrm{Mrad}$ irradiations.

the $\Delta D_{\mathrm{itm}}$ versus $T_{\mathrm{N}}$ of the conventional and the ITN $\mathrm{N}_{2} \mathrm{O}$-nitrided oxides. Clearly, the ITN treated samples are more radiation hard than the conven-

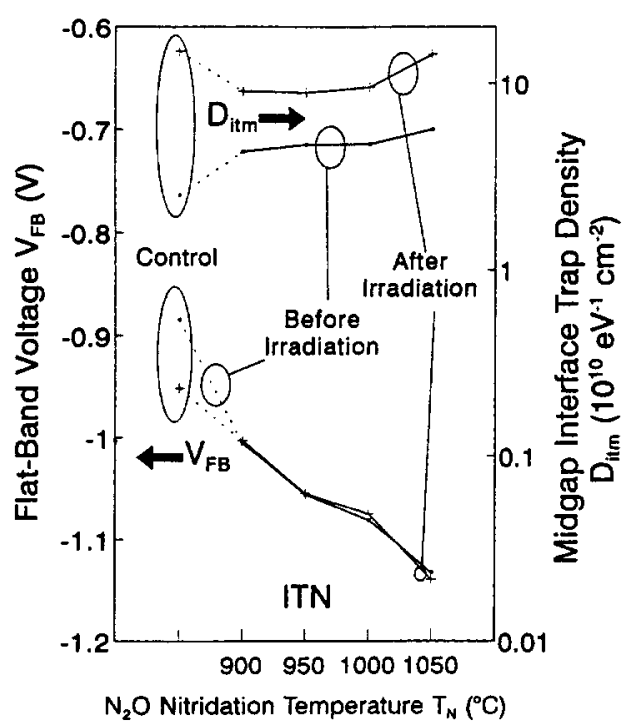

Fig. 7. The flat-band voltage $V_{\mathrm{FB}}$ and midgap interface trap density $D_{\text {itm }}$ versus nitridation temperature $T_{\mathrm{N}}$ curves for the ITN samples before and after ${ }^{60} \mathrm{Co} 1 \mathrm{Mrad}$ irradiations. 
tional samples. Fig. 5 shows $\Delta V_{\mathrm{FB}}$ versus $T_{\mathrm{N}}$ of the conventional and the ITN $\mathrm{N}_{2} \mathrm{O}$-nitrided oxides. Once again, it is seen that the ITN samples exhibit more radiation hardness than the conventional samples.

Figs. 6 and 7 show $D_{\mathrm{itm}}$ and $V_{\mathrm{FB}}$ for the conventional and the ITN samples, respectively, before and after ${ }^{60} \mathrm{Co}$ irradiation with a total dose of $1 \mathrm{Mrad}$. Figs. 6 and 7 show that the high $T_{\mathrm{N}}$ will cause an increase of negative $V_{\mathrm{FB}}$. Apart from the effect of oxide thickness, the incorporation of nitrogen is believed to increase as $T_{\mathrm{N}}$ is increased as stated above. In this work, it is suggested that the proper nitridation temperature is about $900-950^{\circ} \mathrm{C}$. We offer the following explanation for the increased radiation hardness of ITN samples. In conventional thermal oxides, there is a thin strained layer near the $\mathrm{SiO}_{2} / \mathrm{Si}$ interface. After irradiation, the stress in the strained layer is relaxed. At the same time, there are many unsatisfied $\mathrm{Si}$ bonds generated at the $\mathrm{SiO}_{2} / \mathrm{Si}$ interface and in the strained layer. During nitridation, nitrogen atoms interact with these dangling Si bonds. This explains why more nitrogen atoms can be incorporated into the $\mathrm{SiO}_{2} / \mathrm{Si}$ interface and into the oxides. Since $\mathrm{Si}-\mathrm{N}$ bonds are stronger than $\mathrm{Si}-\mathrm{O}$ bonds, more incorporation of nitrogen atoms into the oxide improves its radiation hardness.

\section{Conclusion}

ITN $\mathrm{N}_{2} \mathrm{O}$ nitridation method was shown to improve the radiation hardness of oxides. This occurs because ITN $\mathrm{N}_{2} \mathrm{O}$ nitridation increases the amount of nitrogen incorporated in the oxides in comparison to the amount introduced by conventional $\mathrm{N}_{2} \mathrm{O}$ nitridation.

\section{Acknowledgement}

The authors would like to thank the National Science Council of the Republic of China for supporting this work under contract No. NSC-84-2215E-002-006.

\section{References}

[1] T. Hori, H. Iwasaki and K. Tsuji, IEEE Trans. Electron Devices ED-36 (1989) 340.

[2] H. Fukuda, T. Arakawa and S. Ohno, Electron. Lett. 26 (1990) 1505.

[3] H. Hwang, W. Ting, B. Maiti, D.L. Kwong and J. Lee, Appl. Phys. Lett. 57 (1990) 1010.

[4] W. Ting, H. Hwang, J. Lee and D.L. Kwong, Appl. Phys. Lett. 57 (1990) 2808.

[5] G.W. Yoon, A.B. Joshi, J. Kim and D.L. Kwong, IEEE Electron Device Lett. EDL-14 (1993) 179.

[6] P.J. Wright, A. Kermani and K.C. Saraswat, IEEE Trans. Electron Devices ED-37 (1990) 1836.

[7] T. Hori, H. Iwasaki, Y. Naito and H. Esaki, IEEE Trans. Electron Devices ED-34 (1987) 2238.

[8] M. Bhat, J. Kim, J. Yan, G.W. Yoon, L.K. Han and D.L. Kwong, IEEE Electron Device Lett. EDL-15 (1994) 421.

[9] Wei-Shin Lu, Kuan-Chin Lin and Jenn-Gwo Hwu, IEEE Trans. Electron Devices ED-40 (1993) 1597.

[10] T. Hori, H. Iwasaki and K. Tsuji, IEEE Trans. Electron Devices ED-36 (1989) 340. 